Article

\title{
Performance Comparison of Lattice-Matched AlInN/GaN/AlGaN/GaN Double-Channel Metal-Oxide-Semiconductor High-Electron Mobility Transistors with Planar Channel and Multiple-Mesa-Fin-Channel Array
}

\author{
Hsin-Ying Lee ${ }^{1}\left(\mathbb{D}\right.$, Ying-Hao Ju ${ }^{2}$, Jen-Inn Chyi ${ }^{2}$ and Ching-Ting Lee ${ }^{1,3, * \mathbb{C}}$ \\ 1 Department of Photonics, National Cheng Kung University, Tainan 701, Taiwan; hylee@ee.ncku.edu.tw \\ 2 Department of Electrical Engineering, National Central University, Zhongli 32001, Taiwan; \\ s17howard1001@gmail.com (Y.-H.J.); chyi@ee.ncu.edu.tw (J.-I.C.) \\ 3 Department of Electrical Engineering, Yuan Ze University, Taoyuan 320, Taiwan \\ * Correspondence: ctlee@ee.ncku.edu.tw; Tel.: +886-6-2082368
}

check for

updates

Citation: Lee, H.-Y.; Ju, Y.-H.; Chyi,

J.-I.; Lee, C.-T. Performance

Comparison of Lattice-Matched

AlInN/GaN/AlGaN/GaN

Double-Channel Metal-Oxide-

Semiconductor High-Electron

Mobility Transistors with Planar

Channel and Multiple-Mesa-Fin-

Channel Array. Materials 2022, 15, 42.

https://doi.org/10.3390/ma15010042

Received: 8 October 2021

Accepted: 19 December 2021

Published: 22 December 2021

Publisher's Note: MDPI stays neutral with regard to jurisdictional claims in published maps and institutional affiliations.

Copyright: (C) 2021 by the authors. Licensee MDPI, Basel, Switzerland. This article is an open access article distributed under the terms and conditions of the Creative Commons Attribution (CC BY) license (https:// creativecommons.org/licenses/by/ $4.0 /)$

\begin{abstract}
In this work, $\mathrm{Al}_{0.83} \mathrm{In}_{0.17} \mathrm{~N} / \mathrm{GaN} / \mathrm{Al}_{0.18} \mathrm{Ga}_{0.82} \mathrm{~N} / \mathrm{GaN}$ epitaxial layers used for the fabrication of double-channel metal-oxide-semiconductor high-electron mobility transistors (MOSHEMTs) were grown on silicon substrates using a metalorganic chemical vapor deposition system (MOCVD). A sheet electron density of $1.11 \times 10^{13} \mathrm{~cm}^{-2}$ and an electron mobility of $1770 \mathrm{~cm}^{2} / \mathrm{V}$-s were obtained. Using a vapor cooling condensation system to deposit high insulating 30-nm-thick $\mathrm{Ga}_{2} \mathrm{O}_{3}$ film as a gate oxide layer, double-hump transconductance behaviors with associated double-hump maximum extrinsic transconductances $\left(\mathrm{g}_{\operatorname{mmax}}\right.$ ) of 89.8 and $100.1 \mathrm{mS} / \mathrm{mm}$ were obtained in the double-channel planar MOSHEMTs. However, the double-channel devices with multiple-mesa-fin-channel array with a $g_{\text {mmax }}$ of $148.9 \mathrm{mS} / \mathrm{mm}$ exhibited single-hump transconductance behaviors owing to the better gate control capability. Moreover, the extrinsic unit gain cutoff frequency and maximum oscillation frequency of the devices with planar channel and multiple-mesa-fin-channel array were $5.7 \mathrm{GHz}$ and $10.5 \mathrm{GHz}$, and $6.5 \mathrm{GHz}$ and $12.6 \mathrm{GHz}$, respectively. Hooge's coefficients of $7.50 \times 10^{-5}$ and $6.25 \times 10^{-6}$ were obtained for the devices with planar channel and multiple-mesa-fin-channel array operating at a frequency of $10 \mathrm{~Hz}$, drain-source voltage of $1 \mathrm{~V}$, and gate-source voltage of $5 \mathrm{~V}$, respectively.
\end{abstract}

Keywords: double-channel epitaxial structure; double-hump transconductance; $\mathrm{Ga}_{2} \mathrm{O}_{3}$ gate oxide layer; metal-oxide-semiconductor high-electron mobility transistors

\section{Introduction}

In recent decades, silicon (Si)-based electronic devices have become dominant power devices used in various systems. To enhance their capability of operating at a higher voltage, higher current, higher temperature, higher frequency, and with better energy efficiency, gallium nitride ( $\mathrm{GaN}$ )-based electronic devices have played the mainstream role of power semiconductor devices, which have recently benefited from their superior electrical and physical properties [1-3]. Despite the success of depletion-mode and enhancement-mode GaN-based single-channel metal-oxide-semiconductor high-electron mobility transistors (MOSHEMTs), active development of high-performance compelling devices is still needed. In general, the enhancement of both electron mobility $\left(\mu_{n}\right)$ and sheet electron density $\left(n_{c h}\right)$ has been widely explored with the aim of improving the performances of GaN-based MOSHEMTs. However, it is technically difficult to grow an AlGaN layer with high $\mathrm{Al}$ content to achieve high $\mu_{\mathrm{n}}$ and $\mathrm{n}_{\mathrm{ch}}$ simultaneously. Recently, to simultaneously obtain both the enhanced $\mu_{\mathrm{n}}$ and $\mathrm{n}_{\mathrm{ch}}$, multiple-channel structures were explored [4-7]. Furthermore, superior performances of higher current drive, low resistance, low-frequency noise, and 
improved linearity were demonstrated in multiple-channel MOSHEMTs [8-10]. Nevertheless, since lattice-matched heterostructured structures could reduce the failure caused by the inverse piezoelectric effect [11], lattice-matched barrier layers in multiple-channel structures remain a promising candidate for enhancing performance [12-14]. In this work, double-channel epitaxial layers of lattice-matched $\mathrm{Al}_{0.83} \mathrm{In}_{0.17} \mathrm{~N} / \mathrm{GaN} / \mathrm{Al}_{0.18} \mathrm{Ga}_{0.82} \mathrm{~N} / \mathrm{GaN}$ were grown on $\mathrm{Si}$ substrates using a metalorganic chemical deposition (MOCVD, AIXTRON Group, Herzogenrath, Germany) system. Although several gate oxide layers were used in GaN-based MOSHEMTs [15-20], gallium oxide $\left(\mathrm{Ga}_{2} \mathrm{O}_{3}\right)$-based materials have become promising gate oxide layers due to their superior properties of high breakdown voltage, high radiation resistance, high thermal and chemical stability, high Baliga's figure-of-merit, and better interface properties between $\mathrm{Ga}_{2} \mathrm{O}_{3}$ film and $\mathrm{GaN}$-based semiconductors [21-23]. Furthermore, because high-quality and high-insulating amorphous $\mathrm{Ga}_{2} \mathrm{O}_{3}$ films could be deposited using a vapor cooling condensation system [24,25] and were successfully used in GaN-based MOSHEMTs previously [25,26], the system was used to deposit a 30-nm-thick $\mathrm{Ga}_{2} \mathrm{O}_{3}$ film as a gate oxide layer in this work. In addition, to improve interface properties, surface preparation was employed previously [27]. In this study, before depositing the $\mathrm{Ga}_{2} \mathrm{O}_{3}$ gate oxide layer, an $\left(\mathrm{NH}_{4}\right)_{2} \mathrm{~S}_{\mathrm{x}}$ chemical solution was used to treat the sample surface to completely remove the undesired native oxide residing on the surface of the GaN-based semiconductors [28]. Recently, lattice-matched double-channel AlInN/GaN/AlGaN/GaN MOSHEMTs with multiple-mesa-fin-channel array were reported [29]. Although the compared performances of signal-channel MOSHEMTs with planar channel and multiplemesa-fin-channel array were reported previously [30,31], a comparison of the performances of the multiple-channel MOSHEMTs with planar channel and multiple-mesa-fin-channel array has not yet been carried out. In this work, to compare the performances of the planar channel structure with the multiple-mesa-fin-channel array of double-channel MOSHEMTs, lattice-matched double-channel $\mathrm{Al}_{0.83} \mathrm{In}_{0.17} \mathrm{~N} / \mathrm{GaN} / \mathrm{Al}_{0.18} \mathrm{Ga}_{0.82} \mathrm{~N} / \mathrm{GaN}$ MOSHEMTs with planar channel were fabricated and studied.

\section{Epitaxial Growth and Results}

A MOCVD system was utilized to grow epitaxial layers of $\mathrm{Al}_{0.83} \mathrm{In}_{0.17} \mathrm{~N} / \mathrm{GaN} /$ $\mathrm{Al}_{0.18} \mathrm{Ga}_{0.82} \mathrm{~N} / \mathrm{GaN}$ double-channel structure on $\mathrm{Si}$ substrate. The epitaxial structure included an AIN nucleation layer $(250 \mathrm{~nm})$, a graded AlGaN buffer layer $(1.1 \mu \mathrm{m})$, a trimethylgallium (TMGa)-grown undoped GaN buffer layer $(1.9 \mu \mathrm{m})$, a triethylgallium (TEGa)-grown GaN channel 1 layer $(100 \mathrm{~nm})$, an $\mathrm{AlN}$ spacer layer $(1 \mathrm{~nm})$, an $\mathrm{Al}_{0.18} \mathrm{Ga}_{0.82} \mathrm{~N}$ barrier layer $1(25 \mathrm{~nm})$, a TEGa-grown GaN channel 2 layer $(10 \mathrm{~nm})$, an AlN spacer layer $(1 \mathrm{~nm})$, an $\mathrm{Al}_{0.83} \mathrm{In}_{0.17} \mathrm{~N}$ barrier layer $2(8 \mathrm{~nm})$, and a GaN cap layer $(2 \mathrm{~nm})$. In the epitaxial growth, trimethylgallium (TMAl) and trimethylindium (TMIn) were used as the precursors for $\mathrm{Al}$ and In sources to grow the $\mathrm{Al}_{0.18} \mathrm{Ga}_{0.82} \mathrm{~N}$ barrier layer and the $\mathrm{Al}_{0.83} \mathrm{In}_{0.17} \mathrm{~N}$ barrier layer, respectively. In addition, ammonia $\left(\mathrm{NH}_{3}\right)$ and hydrogen $\left(\mathrm{H}_{2}\right)$ were respectively used as the nitrogen source and carrier gas for growing the 1.1- $\mu \mathrm{m}$-thick graded AlGaN buffer layer and $1.9-\mu \mathrm{m}$-thick $\mathrm{GaN}$ buffer layer. The $\mathrm{H}_{2}$ carrier gas was replaced by nitrogen gas just before and at the end of the growth of the GaN buffer layer without growth interruption. Furthermore, by using a TEGa precursor to grow the GaN channel, the residual carbon concentration could be reduced to improve electron mobility due to the lower channel trapping [32].

Regarding the simulation of a one-dimensional (1D) Schrödinger-Poisson solver, double two-dimensional electron gas (2-DEG) channels were formed at the polarized $\mathrm{Al}_{0.18} \mathrm{Ga}_{0.82} \mathrm{~N} / \mathrm{GaN}$ interface and the band-discontinued lattice-matched $\mathrm{Al}_{0.83} \mathrm{In}_{0.17} \mathrm{~N} / \mathrm{GaN}$ interface [29]. Using a Hall measurement (Ecopia Crop., Anyang, Korea) at room temperature, the equivalent electron mobility of $1770 \mathrm{~cm}^{2} / \mathrm{V}$-s and the equivalent sheet electron density of $1.11 \times 10^{13} \mathrm{~cm}^{-2}$ were measured. To compare the performances of doublechannel MOSHEMTs with planar channel and multiple-mesa-fin-channel array, the same epitaxial layers were used in this work. 


\section{Results and Discussion}

Figure $1 \mathrm{a}$, b present the $3 \mathrm{D}$ schematic configuration of the double-channel $\mathrm{Al}_{0.83} \mathrm{In}_{0.17} \mathrm{~N}$ / $\mathrm{GaN} / \mathrm{Al}_{0.18} \mathrm{Ga}_{0.82} \mathrm{~N} / \mathrm{GaN}$ MOSHEMTs with planar channel and multiple-mesa-fin-channel array, respectively. Under the protection of a patterned 500-nm-thick Ni metal mask, the mesa isolation region $(310 \mu \mathrm{m} \times 320 \mu \mathrm{m})$ of MOSHEMTs was etched down to Si substrate using a reactive-ion etching system with a $\mathrm{BCl}_{3}$ etchant. After removing the Ni mask using an $\mathrm{HCl}$ chemical solution, the sample surface was treated by an $\left(\mathrm{NH}_{4}\right)_{2} \mathrm{~S}_{\mathrm{x}}$ chemical solution at $60^{\circ} \mathrm{C}$ for $30 \mathrm{~min}$ to completely remove undesired native oxide. Using a standard photolithography system to open windows of the source electrode and drain electrode, laminated $\mathrm{Ti} / \mathrm{Al} / \mathrm{Pt} / \mathrm{Au}(25 / 100 / 50 / 400 \mathrm{~nm})$ metals were sequentially deposited and were then lifted off. By annealing the sample in a nitrogen environmental rapid-thermal annealing system at $850{ }^{\circ} \mathrm{C}$ for $1 \mathrm{~min}$, an ohmic-contacted source electrode and drain electrode with a specific contact resistance of about $7.5 \times 10^{-6} \Omega-\mathrm{cm}^{2}$ were obtained. The separation between the source electrode and the drain electrode was $10 \mu \mathrm{m}$. After depositing a $\mathrm{ZnO}$ film $(300 \mathrm{~nm})$, the gate windows (length $=1 \mu \mathrm{m}$ and width $=50 \mu \mathrm{m})$ placed at the central region between the source electrode and drain electrode were etched using a diluted $\mathrm{HCl}$ chemical solution under a photoresist mask. When the sample was repeatedly treated with a $\left(\mathrm{NH}_{4}\right)_{2} \mathrm{~S}_{\mathrm{x}}$ chemical solution, a 30 -nm-thick $\mathrm{Ga}_{2} \mathrm{O}_{3}$ film was deposited at about $80 \mathrm{~K}$ as the gate oxide layer using a vapor cooling condensation system. The deposition process and electrical properties of the amorphous $\mathrm{Ga}_{2} \mathrm{O}_{3}$ films deposited using this system were reported previously $[25,33]$. Prior to removing the $\mathrm{ZnO}$ mask, laminated $\mathrm{Ni} / \mathrm{Au}$ $(20 / 300 \mathrm{~nm})$ gate metals were sequentially deposited by an electron beam evaporator. The double-channel planar $\mathrm{Al}_{0.83} \mathrm{In}_{0.17} \mathrm{~N} / \mathrm{GaN} / \mathrm{Al}_{0.18} \mathrm{Ga}_{0.82} \mathrm{~N} / \mathrm{GaN}$ MOSHEMTs have a channel length of $10 \mu \mathrm{m}$ and a channel width of $50 \mu \mathrm{m}$. In the same batch process, two samples of the double-channel MOSHEMTs with planar channel and multiple-mesa-fin-channel array were fabricated. Every sample included more than 200 devices. The uniformity and performance reproducibility of the MOSHEMTs were good.

In addition to the 500-nm-wide strip channel array patterned using an He-Cd laser interference photolithography system, similar fabrication processes of planar devices were utilized for fabricating devices with multiple-mesa-fin-channel array. However, within the same channel width of $50 \mu \mathrm{m}$, the total real channel width in the multiple-mesa-fin-channel array was $25.2 \mu \mathrm{m}[29]$.

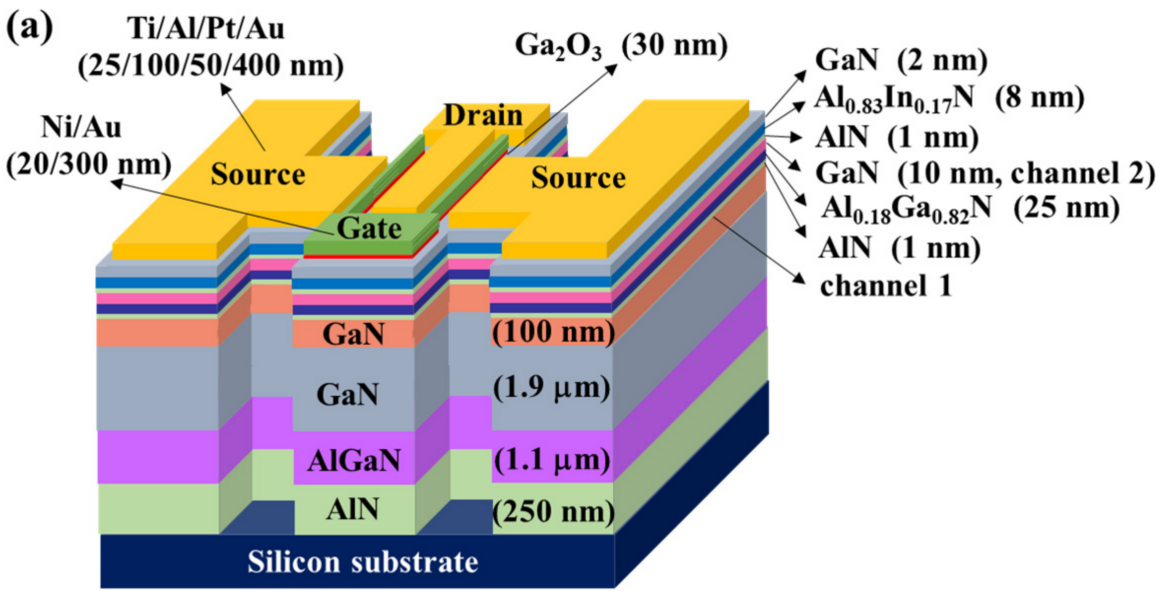

Figure 1. Cont. 


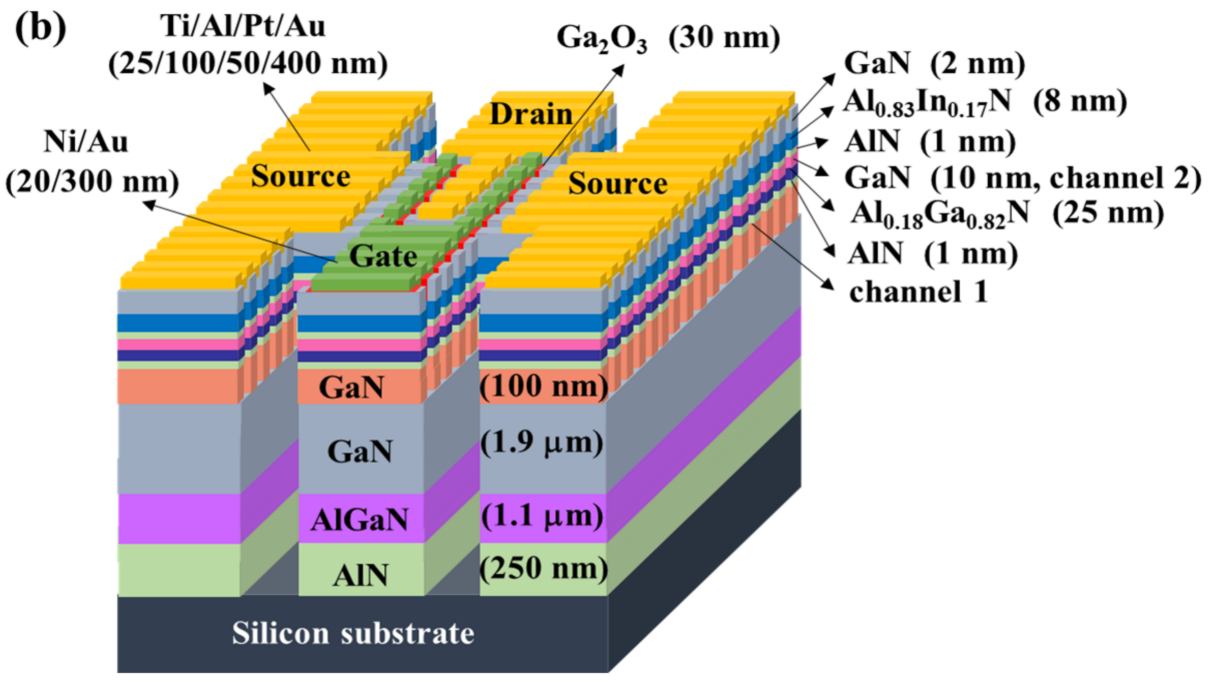

Figure 1. Epitaxial structure and three-dimensional schematic configuration of double-channel MOSHEMTs with (a) planar channel and (b) multiple-mesa-fin-channel array.

Using the measurement of an Agilent 4156C semiconductor parameter analyzer, Figure $2 \mathrm{a}, \mathrm{b}$ respectively illustrate the typical drain-source current $\left(\mathrm{I}_{\mathrm{DS}}\right)$-drain-source voltage $\left(\mathrm{V}_{\mathrm{DS}}\right)$ characteristics of the devices with planar channel and multiple-mesa-finchannel array operating at various gate-source voltages $\left(\mathrm{V}_{\mathrm{GS}}\right)$. By normalizing the channel width of $50 \mu \mathrm{m}$, the normalized saturation drain-source current ( $\left.\mathrm{I}_{\mathrm{DSS}}\right)$ of the planar devices operating at $\mathrm{V}_{\mathrm{GS}}=5 \mathrm{~V}$ and $\mathrm{V}_{\mathrm{DS}}=10 \mathrm{~V}$ was $520.0 \mathrm{~mA} / \mathrm{mm}$, in which the real drainsource current was $26.0 \mathrm{~mA}$. For the devices with multiple-mesa-fin-channel array, the IDSS was $842.7 \mathrm{~mA} / \mathrm{mm}$, in which the real drain-source current was $21.2 \mathrm{~mA}$. It was worth noting that the real drain-source current in the devices with multiple-mesa-fin-channel array was less than that of the planar devices. When the on-resistance $\left(R_{o n}\right)$ of the devices was defined as the inverse slope of the $I_{D S}-V_{D S}$ characteristics at $V_{D S}=0 V$ and $V_{\mathrm{GS}}=5 \mathrm{~V}$, the $R_{\mathrm{on}}=10.2 \Omega$-mm of the planar devices was calculated and compared with the $\mathrm{R}_{\mathrm{on}}=6.1 \Omega$-mm of the devices with multiple-mesa-fin-channel array [29].

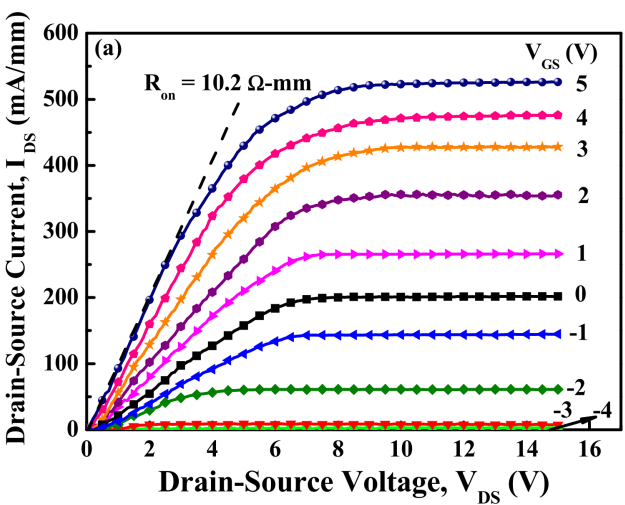

(a)

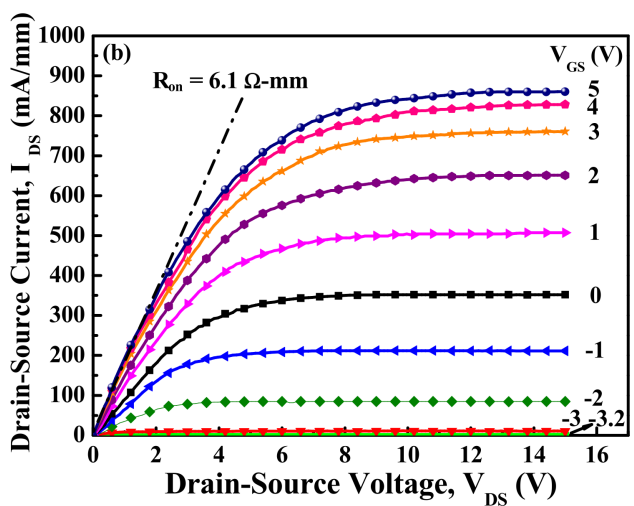

(b)

Figure 2. Typical drain-source current-drain-source voltage characteristics of double-channel MOSHEMTs with (a) planar channel and (b) multiple-mesa-fin-channel array [29].

Figure 3 presents the $I_{D S}-V_{G S}$ characteristics and the extrinsic transconductance $\left(\mathrm{g}_{\mathrm{m}}\right)-\mathrm{V}_{\mathrm{GS}}$ characteristics of the devices with planar channel and multiple-mesa-fin-channel array operating at $V_{D S}=10 \mathrm{~V}$. In the $g_{m}-V_{G S}$ characteristics shown in Figure 3, a doublehump transconductance performance was clearly observed in the planar devices; it corresponded to the effective gate modulation of the upper channel 2 and the lower channel 1, 
respectively. The maximum extrinsic transconductance ( $\left.\mathrm{g}_{\mathrm{mmax}}\right)$ of the double-hump behavior was 89.8 and $100.1 \mathrm{mS} / \mathrm{mm}$, respectively. It was worth noting that the double-hump transconductance performance was not found in the devices with a multiple-mesa-finchannel structure due to the better gate control capability caused by the modulation of the side-wall electrical field in the fin-channel [31]. In addition, the $g_{\operatorname{mmax}}$ of $148.9 \mathrm{mS} / \mathrm{mm}$ was obtained in the single-hump transconductance. Compared with the performances of the devices with planar channel, the higher normalized saturation current, higher maximum extrinsic transconductance, and lower on-resistance in the devices with multiple-mesa-finchannel array were contributed by the lower real drain-source current and the better heat dissipation driven by lateral heat flow within the fin-channel array [31]. If the threshold voltage $\left(V_{\text {th }}\right)$ of the devices was defined as the $V_{G S}$ corresponding to the $I_{D S}=1 \mu \mathrm{A} / \mathrm{mm}$, the $\mathrm{V}_{\text {th }}$ of the planar devices was $-3.8 \mathrm{~V}$. Compared with a $\mathrm{V}_{\text {th }}$ of $-3.2 \mathrm{~V}$ in the devices with a multiple-fin-channel array structure, the $\mathrm{V}_{\text {th }}$ was pushed toward a more positive value due to the early pinched-off effect $[30,34]$.

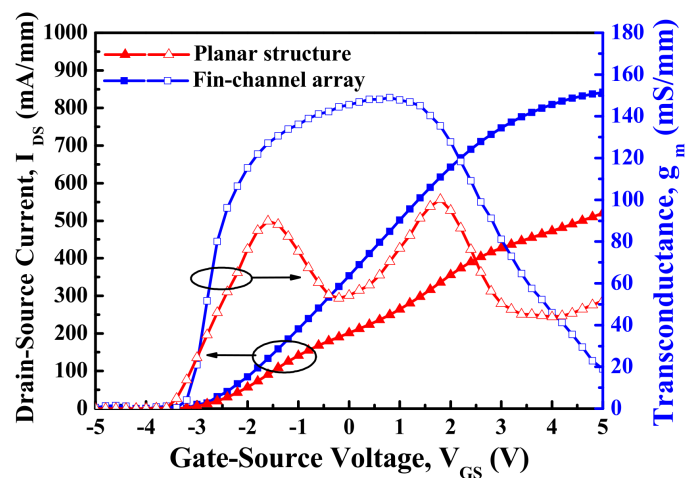

Figure 3. Drain-source current-gate-source voltage characteristics and extrinsic transconductance/gatesource voltage characteristics of double-channel MOSHEMTs operating at drain-source voltage of $10 \mathrm{~V}$.

An Agilent 8510C network analyzer (Agilent, CA, USA) was used to measure smallsignal high-frequency performances of the MOSHEMTs. Figure 4 illustrates frequencydependent short-circuit current gain and frequency-dependent maximum available power gain of the devices with planar channel and multiple-mesa-fin-channel array. The extrinsic unit gain cutoff frequency $\left(\mathrm{f}_{\mathrm{T}}\right)$ of $5.7 \mathrm{GHz}$ and the maximum oscillation frequency $\left(\mathrm{f}_{\max }\right)$ of $10.5 \mathrm{GHz}$ of the planar devices were obtained. For the MOSHEMTs with multiplemesa-fin-channel array, the $\mathrm{f}_{\mathrm{T}}$ and $\mathrm{f}_{\max }$ were $6.5 \mathrm{GHz}$ and $12.6 \mathrm{GHz}$, respectively [29].

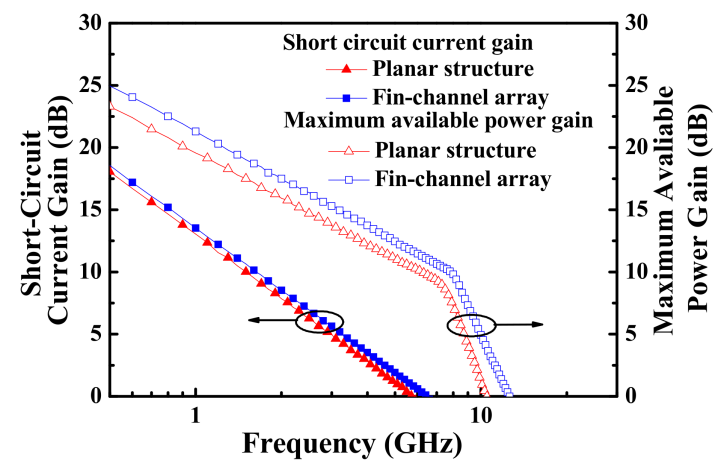

Figure 4. Short-circuit current gain and maximum available power gain as a function of frequency of double-channel MOSHEMTs.

In general, the low-frequency noise behaviors could be used to evaluate electron trapping and electron detrapping effects induced by traps, defects, and interface states in electronic devices [35]. The low-frequency noise characteristics of both the devices were measured using an Agilent 4156C low-noise bias supply, an HP 35670A dynamic 
signal analyzer, and a BTA 9812B noise analyzer. Figure 5 presents the normalized lowfrequency noise power density $\left(\mathrm{S}_{\mathrm{IDS}}(\mathrm{f}) / \mathrm{I}_{\mathrm{DS}}{ }^{2}\right)$-frequency $(\mathrm{f})$ characteristics of the devices with planar channel and multiple-mesa-fin-channel array operating at $V_{D S}=1 \mathrm{~V}$. As shown in Figure 5, the normalized noise power density decreased with an increase in $\mathrm{V}_{\mathrm{GS}}$ voltage. The $\mathrm{S}_{\mathrm{IDS}}(\mathrm{f}) / \mathrm{I}_{\mathrm{DS}}{ }^{2}$ was about $5.4 \times 10^{-13} \mathrm{~Hz}^{-1}$ and $8.7 \times 10^{-14} \mathrm{~Hz}^{-1}$ for the devices with planar channel and multiple-mesa-fin-channel array operating at $\mathrm{V}_{\mathrm{GS}}=5 \mathrm{~V}$ and $\mathrm{V}_{\mathrm{DS}}=1 \mathrm{~V}$ at $\mathrm{f}=10 \mathrm{~Hz}$. Under the same operating conditions, the higher normalized noise power density in the planar devices was attributed to the larger channel area. Generally, Hooge's coefficient $\alpha$ provided a useful figure-of-merit for evaluating electronic devices. The $\alpha$ value could be calculated as follows [36]:

$$
\alpha=\left(\mathrm{S}_{\mathrm{IDS}}(\mathrm{f}) / \mathrm{I}_{\mathrm{DS}}{ }^{2}\right) \cdot \mathrm{f} \cdot\left(\mathrm{L}_{\mathrm{G}} \mathrm{W}_{\mathrm{G}} \mathrm{n}_{\mathrm{ch}}\left(\mathrm{V}_{\mathrm{GS}}-\mathrm{V}_{\mathrm{th}}\right) /\left|\mathrm{V}_{\mathrm{th}}\right|\right)
$$

where $\mathrm{L}_{\mathrm{G}}=1 \mu \mathrm{m}$ is gate length and $\mathrm{n}_{\mathrm{ch}}=1.11 \times 10^{13} \mathrm{~cm}^{-2}$ is channel electron density. In the planar devices, the gate width $\mathrm{W}_{\mathrm{G}}$ is $50 \mu \mathrm{m}$ and the threshold voltage $\mathrm{V}_{\text {th }}$ is $-3.8 \mathrm{~V}$, while $\mathrm{W}_{\mathrm{G}}$ is $25.2 \mu \mathrm{m}$ and $\mathrm{V}_{\text {th }}$ is $-3.2 \mathrm{~V}$ in the devices with multiple-mesa-fin-channel array. The calculated $\alpha$ value of $7.50 \times 10^{-5}$ and $6.25 \times 10^{-6}$ for the MOSHEMTs with planar channel and multiple-mesa-fin-channel array operating at $\mathrm{f}=10 \mathrm{~Hz}, \mathrm{~V}_{\mathrm{GS}}=5 \mathrm{~V}$, and $\mathrm{V}_{\mathrm{DS}}=1 \mathrm{~V}$ was obtained. In addition to the result of low Hooge's coefficient, the normalized noise power density was well fixed at $1 / \mathrm{f}$. This behavior could imply that the flicker noise was the dominant noise in the devices.

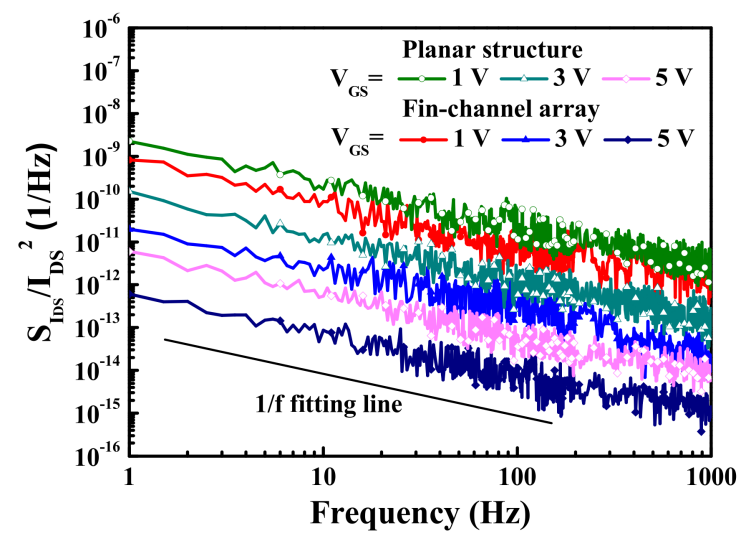

Figure 5. Frequency-dependent normalized noise power density spectra of double-channel MOSHEMTs operating at drain-source voltage of $1 \mathrm{~V}$.

\section{Conclusions}

Recently, planar channel structures and multiple-mesa-fin-channel array structures have been widely used for the fabrication of MOSHEMTs. In this study, to compare the performance of planar channel and multiple-mesa-fin-channel array used in double-channel MOSHEMTs, double-channel $\mathrm{Al}_{0.83} \mathrm{In}_{0.17} \mathrm{~N} / \mathrm{GaN} / \mathrm{Al}_{0.18} \mathrm{Ga}_{0.82} \mathrm{~N} / \mathrm{GaN}$ epitaxial layers were grown on Si substrates using an MOCVD system. The performance comparisons of the double-channel MOSHEMTs with planar channel and multiple-mesa-fin-channel array are listed in Table 1. Compared with the performance of the double-channel MOSHEMTs with multiple-mesa-fin-channel array, double-hump transconductance behavior was observed in the double-channel planar MOSHEMTs owing to the effective gate modulation of the upper channel 2 and the lower channel 1 by the only top-side electrical field. However, in addition to the modulation of the top-side electrical field, the side-wall electric field in the multiple-mesa-fin-channel could perform at a better gate control capability. Consequently, the transconductance collapse was paved in the multiple-mesa-fin-channel. It was expected that the pavement efficiency could be enhanced by using narrower fin-channel. The extrinsic maximum double-hump transconductances of the double-channel planar MOSHEMTs were 89.8 and $100.1 \mathrm{mS} / \mathrm{mm}$, respectively. In addition, the extrinsic maximum 
transconductance of the double-channel MOSHEMTs with multiple-mesa-fin-channel array was $148.9 \mathrm{mS} / \mathrm{mm}$. Furthermore, compared with the performances of MOSHEMTs with a planar channel structure, better heat dissipation driven by the lateral heat flow in the parallel fin-channels could improve the direct-current performances and high-frequency performances [37]. The extrinsic unit gain cutoff frequency and maximum oscillation frequency of the MOSHEMTs with planar channel and multiple-mesa-fin-channel array were 5.7 and $10.5 \mathrm{GHz}$, and 6.5 and $12.6 \mathrm{GHz}$, respectively. Owing to the screening effect of the trapping probability, better noise performances were obtained in the MOSHEMTs with multiple-mesa-fin-channel array $[31,38]$. Hooge's coefficient of the MOSHEMTs with planar channel and multiple-mesa-fin-channel array was $7.50 \times 10^{-5}$ and $6.25 \times 10^{-6}$, respectively. Although the multiple-mesa-fin-channel array exhibited superior advantages to the MOSHEMTs, its real drain-source current was less than that in the planar devices with the same channel width. Evaluating the power performances of devices with multiple-mesa-fin-channel array remains a challenging task.

Recently, planar channel structures and multiple-mesa-fin-channel array structures have been widely used for the fabrication of MOSHEMTs. In this study, to compare the performance of planar channel and multiple-mesa-fin-channel array used in double-channel MOSHEMTs, double-channel $\mathrm{Al}_{0.83} \mathrm{In}_{0.17} \mathrm{~N} / \mathrm{GaN} / \mathrm{Al}_{0.18} \mathrm{Ga}_{0.82} \mathrm{~N} / \mathrm{GaN}$ epitaxial layers were grown on Si substrates using an MOCVD system. The performance comparisons of the double-channel MOSHEMTs with planar channel and multiple-mesa-fin-channel array are listed in Table 1. Compared with the performance of the double-channel MOSHEMTs with multiple-mesa-fin-channel array, double-hump transconductance behavior was observed in the double-channel planar MOSHEMTs owing to the effective gate modulation of the upper channel 2 and the lower channel 1 by the only top-side electrical field. However, in addition to the modulation of the top-side electrical field, the side-wall electric field in the multiple-mesa-fin-channel could perform at a better gate control capability. Consequently, the transconductance collapse was paved in the multiple-mesa-fin-channel. It was expected that the pavement efficiency could be enhanced by using narrower fin-channel. The extrinsic maximum double-hump transconductances of the double-channel planar MOSHEMTs were 89.8 and $100.1 \mathrm{mS} / \mathrm{mm}$, respectively. In addition, the extrinsic maximum transconductance of the double-channel MOSHEMTs with multiple-mesa-fin-channel array was $148.9 \mathrm{mS} / \mathrm{mm}$. Furthermore, compared with the performances of MOSHEMTs with a planar channel structure, better heat dissipation driven by the lateral heat flow in the parallel fin-channels could improve the direct-current performances and high-frequency performances [37]. The extrinsic unit gain cutoff frequency and maximum oscillation frequency of the MOSHEMTs with planar channel and multiple-mesa-fin-channel array were 5.7 and $10.5 \mathrm{GHz}$, and 6.5 and $12.6 \mathrm{GHz}$, respectively. Owing to the screening effect of the trapping probability, better noise performances were obtained in the MOSHEMTs with multiple-mesa-fin-channel array $[31,38]$. Hooge's coefficient of the MOSHEMTs with planar channel and multiple-mesa-fin-channel array was $7.50 \times 10^{-5}$ and $6.25 \times 10^{-6}$, respectively. Although the multiple-mesa-fin-channel array exhibited superior advantages to the MOSHEMTs, its real drain-source current was less than that in the planar devices with the same channel width. Evaluating the power performances of devices with multiple-mesa-fin-channel array remains a challenging task. 
Table 1. Performance comparisons of the double-channel MOSHEMTs with planar channel and multiple-mesa-fin-channel array.

\begin{tabular}{ccc}
\hline MOSHEMTs & Planar Channel & $\begin{array}{c}\text { Multiple-Mesa-Fin-Channel } \\
\text { Array }\end{array}$ \\
\hline $\begin{array}{c}\text { Drain-source current, } \mathrm{I}_{\mathrm{DS}} \\
\text { at } \mathrm{V}_{\mathrm{DS}}=10 \mathrm{~V} \text { and } \mathrm{V}_{\mathrm{GS}}=5 \mathrm{~V} \\
\text { on-resistance, } \mathrm{R}_{\mathrm{On}}\end{array}$ & $520.0 \mathrm{~mA} / \mathrm{mm}$ & $842.7 \mathrm{~mA} / \mathrm{mm}$ \\
$\begin{array}{c}\text { at } \mathrm{V}_{\mathrm{DS}}=0 \mathrm{~V} \text { and } \mathrm{V}_{\mathrm{GS}}=5 \mathrm{~V} \\
\text { Transconductance, } \mathrm{g}_{\mathrm{m}}\end{array}$ & $10.2 \Omega-\mathrm{mm}$ & $6.1 \Omega-\mathrm{mm}$ \\
$\begin{array}{c}\text { at } \mathrm{V}_{\mathrm{DS}}=10 \mathrm{~V} \\
\begin{array}{c}\text { Threshold voltage, } \mathrm{V}_{\mathrm{th}} \\
\text { at } \mathrm{I}_{\mathrm{DS}}=1 \mu \mathrm{A} / \mathrm{mm}\end{array}\end{array}$ & 89.8 and $100.1 \mathrm{mS} / \mathrm{mm}$ \\
$\begin{array}{c}\text { Unit gain cutoff frequency, } \mathrm{f}_{\mathrm{T}} \\
\text { Maximum oscillation } \\
\text { frequency, } \mathrm{f}_{\text {max }}\end{array}$ & $-3.8 \mathrm{~V}$ & $148.9 \mathrm{mS} / \mathrm{mm}$ \\
Hooge's coefficient, $\alpha$ & $5.7 \mathrm{GHz}$ & $-3.2 \mathrm{~V}$ \\
\hline
\end{tabular}

Author Contributions: Conceptualization, C.-T.L.; data curation, H.-Y.L.; software and epitaxial growth, Y.-H.J. and J.-I.C. funding acquisition, C.-T.L.; investigation, H.-Y.L. and C.-T.L.; writingoriginal draft, C.-T.L.; writing-review and editing, H.-Y.L. and C.-T.L. All authors have read and agreed to the published version of the manuscript.

Funding: This research was funded by the Ministry of Science and Technology of Taiwan under the grants of MOST 109-2923-E-155-001, MOST 108-2221-E-006-215-MY3, and MOST 108-2221-E-155-029MY3.

Institutional Review Board Statement: Not applicable.

Informed Consent Statement: Not applicable.

Data Availability Statement: The data presented in this study are available on request from the corresponding author.

Acknowledgments: The authors appreciate the financial support from the Ministry of Science and Technology of Taiwan.

Conflicts of Interest: The authors declare no conflict of interest.

\section{References}

1. Roccaforte, F.; Greco, G.; Fiorenza, P.; Iucolano, F. An overview of normally-off GaN-based high electron mobility transistors. Materials 2019, 12, 1599. [CrossRef]

2. $\quad$ Lee, H.Y.; Lin, C.H.; Wei, C.C.; Yang, J.C.; Chang, E.Y.; Lee, C.T. AlGaN/GaN enhancement-mode MOSHEMTs utilizing hybrid gate-recessed structure and ferroelectric charge trapping/storage stacked $\mathrm{LiNbO} / \mathrm{HfO}_{2} / \mathrm{Al}_{2} \mathrm{O}_{3}$ structure. IEEE Trans. Electron Devices 2021, 68, 3768-3774. [CrossRef]

3. Zhang, S.; Ma, B.; Zhou, X.; Hua, Q.; Gong, J.; Liu, T.; Cui, X.; Zhu, J.; Guo, W.; Jing, L.; et al. Strain-controlled power devices as inspired by human reflex. Nat. Commun. 2020, 11, 326. [CrossRef] [PubMed]

4. Heikman, S.; Keller, S.; Green, D.S.; DenBaars, S.P.; Mishra, U.K. High conductivity modulation doped AlGaN/GaN multiple channel heterostructures. J. Appl. Phys. 2003, 94, 5321-5325. [CrossRef]

5. Chu, R.; Zhou, Y.; Liu, J.; Wang, D.; Chen, K.J.; Lau, K.M. AlGaN-GaN double-channel HEMTs. IEEE Trans. Electron Devices 2005, 52, 438-446. [CrossRef]

6. Erine, C.; Ma, J.; Santoruvo, G.; Matioli, E. Multi-channel AlGaN/GaN In-plane-gate field-effect transistors. IEEE Electron Device Lett. 2020, 41, 321-324. [CrossRef]

7. Chen, X.; Lv, D.D.; Zhang, J.F.; Zhou, H.; Ren, Z.Y.; Wang, C.; Wu, Y.; Wang, D.; Zhang, H.; Lei, Y.Y. Model of electron population and energy band diagram of multiple-channel GaN heterostructures. IEEE Trans. Electron Devices 2021, 68, 1557-1562. [CrossRef]

8. Kamath, A.; Patil, T.; Adari, R.; Bhattacharya, I.; Ganguly, S.; Aldhaheri, R.W.; Hussain, M.A.; Saha, D. Double-channel AlGaN/GaN high electron mobility transistor with back barriers. IEEE Electron Device Lett. 2012, 33, 1690-1692. [CrossRef]

9. Wei, J.; Liu, S.; Li, B.; Tang, X.; Lu, Y.; Liu, C.; Hua, M.; Zhang, Z.; Tang, G.; Chen, K.J. Low on-resistance normally-off GaN double-channel metal-oxide-semiconductor high-electron-mobility transistor. IEEE Electron Device Lett. 2015, 36, 1287-1290. [CrossRef]

10. Jha, S.K.; Surya, C.; Chen, K.J.; Lau, K.M.; Jelencovic, E. Low-frequency noise properties of double channel AlGaN/GaN HEMTs. Solid-State Electron. 2008, 21, 606-611. [CrossRef] 
11. Joh, J.; Gao, F.; Palacios, T.; del Alamo, J.A. A model for the critical voltage for electrical degradation of GaN high electron mobility transistors. Microelectron. Reliab. 2010, 50, 767-773. [CrossRef]

12. Lim, T.; Aidam, R.; Waltereit, P.; Henkel, T.; Quay, R.; Lozar, R.; Maier, T.; Kirste, L.; Ambacher, O. GaN-based submicrometer HEMTs with lattice-matched InAlGaN barrier grown by MBE. IEEE Electron Device Lett. 2010, 31, 671-673. [CrossRef]

13. Mojaver, H.R.; Gosselin, J.L.; Valizadeh, P. Use of a bilayer lattice-matched AlInGaN barrier for improving the channel carrier confinement of enhancement-mode AlInGaN/GaN hetero-structure field-effect transistors. J. Appl. Phys. 2017, 121, 244502. [CrossRef]

14. Shrestha, N.M.; Li, Y.; Chen, C.H.; Sanyal, I.; Tarng, J.H.; Chyi, J.I.; Samukawa, S. Design and simulation of high performance lattice matched double barrier normally off AlInGaN/GaN HEMTs. IEEE J. Electron. Devices Soc. 2020, 8, 873-878. [CrossRef]

15. Chiou, Y.L.; Lee, C.T. Band alignment and performance improvement mechanisms of chlorine-treated ZnO-gate AlGaN/GaN metal-oxide-semiconductor high-electron mobility transistors. IEEE Trans. Electron Devices 2011, 58, 3869-3875. [CrossRef]

16. Kim, H.S.; Kang, M.J.; Kim, J.J.; Seo, K.S.; Cha, H.Y. Effects of recessed-gate structure on AlGaN/GaN-on-SiC MIS-HEMTs with thin $\mathrm{AlO}_{\mathrm{x}} \mathrm{N}_{\mathrm{y}}$ MIS gate. Materials 2020, 13, 1538. [CrossRef] [PubMed]

17. Lee, C.T.; Yang, C.L.; Tseng, C.Y.; Chang, J.H.; Horng, R.H. GaN-based enhancement-mode metal-oxide-semiconductor highelectron mobility transistors using $\mathrm{LiNbO}_{3}$ ferroelectric insulator on gate-recessed structure. IEEE Trans. Electron Devices 2015, 62, 2481-2487. [CrossRef]

18. Eller, B.S.; Yang, J.; Nemanich, R.J. Electronic surface and dielectric interface states on GaN and AlGaN. J. Vac. Sci. Technol. A 2013, 31, 050807. [CrossRef]

19. Zhang, S.; Wei, K.; Zhang, Y.C.; Chen, X.J.; Huang, S.; Yin, H.B.; Liu, G.G.; Yuan, T.T.; Zheng, Y.K.; Wang, X.H.; et al. Wellsuppressed interface states and improved transport properties of AlGaN/GaN MIS-HEMTs with PEALD SiN gate dielectric. Vacuum 2021, 191, 110359. [CrossRef]

20. Zheng, Z.; Zhang, L.; Song, W.; Feng, S.; Xu, H.; Sun, J.; Yang, S.; Chen, T.; Wei, J.; Chen, K.J. Gallium nitride-based complementary logic integrated circuits. Nat. Electron. 2021, 4, 595-604. [CrossRef]

21. Pearton, S.J.; Yang, J.; Cary IV, P.H.; Ren, F.; Kim, J.; Tadjer, M.J.; Mastro, M.A. A review of $\mathrm{Ga}_{2} \mathrm{O}_{3}$ materials, processing, and devices. Appl. Phys. Rev. 2018, 5, 011301. [CrossRef]

22. Oon, H.S.; Cheong, K.Y. Recent development of gallium oxide thin film on GaN. Mater. Sci. Semicond. Process. 2013, 16, 1217-1231. [CrossRef]

23. Shih, H.Y.; Chu, F.C.; Das, A.; Lee, C.Y.; Chen, M.J.; Lin, R.M. Atomic layer deposition of gallium oxide films as gate dielectrics in AlGaN/GaN metal-oxide-semiconductor high-electron mobility transistors. Nanoscale Res. Lett. 2016, 11, 235. [CrossRef]

24. Lin, C.H.; Lee, C.T. $\mathrm{Ga}_{2} \mathrm{O}_{3}$-based solar-blind deep ultraviolet light-emitting diodes. J. Lumines. 2020, 224, 117326. [CrossRef]

25. Lee, H.Y.; Chang, T.W.; Lee, C.T. AlGaN/GaN metal-oxide-semiconductor high-electron mobility transistors using $\mathrm{Ga}_{2} \mathrm{O}_{3}$ gate dielectric layer grown by vapor cooling condensation system. J. Electron. Mater. 2021, 50, 3748-3753. [CrossRef]

26. Lee, H.Y.; Chang, T.W.; Chang, E.Y.; Rorsman, N.; Lee, C.T. Fabrication and characterization of GaN-based fin-channel array metal-oxide-semiconductor high-electron mobility transistors with recessed-gate and $\mathrm{Ga}_{2} \mathrm{O}_{3}$ gate insulator layer. IEEE J. Electron Devices Soc. 2021, 9, 393-399. [CrossRef]

27. Chakroun, A.; Maher, M.; Al Alam, E.; Souifi, A.; Aimez, V.; Arès, R.; Jaouad, A. Optimized pre-treatment process for MOS-GaN devices passivation. IEEE Electron Device Lett. 2014, 35, 318-320. [CrossRef]

28. Lin, Y.J.; Lee, C.T.; Chang, H.C. Changes in activation energies of donors and carrier concentration in Si-doped n-type GaN due to $\left(\mathrm{NH}_{4}\right)_{2} \mathrm{~S}_{\mathrm{x}}$ treatment. Semicon. Sci. Technol. 2006, 21, 1167-1171. [CrossRef]

29. Lee, H.Y.; Liu, D.S.; Chyi, J.I.; Chang, E.Y.; Lee, C.T. Lattice-matched AlInN/GaN/AlGaN/GaN heterostructured-double-channel metal-oxide-semiconductor high-electron mobility transistors with multiple-mesa-fin-channel array. Materials 2021, 14, 5474 [CrossRef]

30. Lee, C.T.; Guo, J.C. Fin-gated nanochannel array gate-recessed AlGaN/GaN metal-oxide-semiconductor high-electron-mobility transistors. IEEE Trans. Electron Devices 2020, 67, 1939-1945. [CrossRef]

31. Jia, J.J.; Lin, C.C.; Lee, C.T. Scaling effect in gate-recessed AlGaN/GaN fin-nanochannel array MOSHEMTs. IEEE Access 2020, 8 , 158941-158946. [CrossRef]

32. Sanyal, I.; Lee, Y.C.; Chyi, J.I.; Lin, K.L. High electron mobility AlInGaN/AlN/GaN heterostructures grown on 150-mm silicon substrate. SPIE Photonics West Proc. 2018, 10532, 1053213. [CrossRef]

33. Lee, H.Y.; Lin, C.H.; Lee, C.T. Whole metal oxide p-i-n deep ultraviolet light-emitting diodes using i-Ga ${ }_{2} \mathrm{O}_{3}$ active emissive film. IEEE Photon. Technol. Lett. 2020, 32, 941-943. [CrossRef]

34. Lu, B.; Matioli, E.; Palacios, T. Tri-gate normally-off GaN Power MISFET. IEEE Electron Device Lett. 2012, 33, 360-362. [CrossRef]

35. Levinshtein, M.E.; Rumyantsev, S.L.; Gaska, R.; Yang, J.W.; Shur, M.S. AlGaN/GaN high electron mobility field effect transistors with low 1/f noise. Appl. Phys. Lett. 1998, 73, 1089-1091. [CrossRef]

36. Hooge, F.N.; Kleinpenning, T.G.M.; Vandamme, L.K.J. Experimental studies on 1/f noise, Rep. Prog. Phys. 1981, 44, 479-532. [CrossRef]

37. Mikulics, M.; Kordoš, P.; Fox, A.; Kočan, M.; Lüth, H.; Sofer, Z.; Hardtdegen, H. Efficient heat dissipation in AlGaN/GaN heterostructure grown on silver substrate. Appl. Mater. Today 2017, 7, 134-137. [CrossRef]

38. Vodapally, S.; Theodorou, C.G.; Bae, Y.; Ghibaudo, G.; Cristoloveanu, S.; Im, K.S.; Lee, J.H. Comparison for 1/f noise characteristics of AlGaN/GaN FinFET and planar MISHFET. IEEE Trans. Electron Devices 2017, 64, 3634-3638. [CrossRef] 